\title{
An applicable nitrogen supply strategy for attached cultivation of Aucutodesmus obliquus
}

\author{
Chunli Ji • Junfeng Wang • Wei Zhang • Jinli Liu • \\ Hui Wang • Lili Gao • Tianzhong Liu
}

Received: 3 May 2013 /Revised and accepted: 15 August 2013 /Published online: 5 September 2013

(C) Springer Science+Business Media Dordrecht 2013

\begin{abstract}
The "attached cultivation" method of microalgae in which the wet paste of algal biomass is attached onto supporting materials to form an immobilized biofilm layer, and the culture medium is supplied to this layer to provide nutrients and moisture for growth was highly efficient in biomass production and represents a promising technology to improve the biofuel industry. To optimize the nitrogen supply strategy for this attached cultivation method, the growth and total lipids accumulation properties for the green alga Aucutodesmus obliquus with this method were studied under different quantities of nitrogen source and different volumes of aqueous medium that continuously circulated inside the photobioreactor. Results showed that, compared with medium volume, the nitrogen quantity was a stronger factor affecting the growth and total lipid accumulation. An optimized nitrogen supply strategy for the attached cultivation of $A$. obliquus is proposed as circulating ca. $60 \mathrm{~L}$ of BG-11 medium containing $1 / 10$ of nitrate concentration for $1 \mathrm{~m}^{2}$ of cultivation surface. With this strategy, the attached $A$. obliquus accumulated biomass and total lipids simultaneously and obtained a high triacylglyceride productivity of $2.53 \mathrm{~g} \mathrm{~m}^{-2}$ day $^{-1}$ in 7 days under subsaturated illumination of $100 \mu \mathrm{mol}$ photons $\mathrm{m}^{-2} \mathrm{~s}^{-1}$. The water usage of $60 \mathrm{~L} \mathrm{~m}^{-2}$ was potentially decreased to $<2 \mathrm{~L} \mathrm{~m}^{-2}$ if the nutrient supply was further improved. Dissolving the nitrogen source in small volume was the best
\end{abstract}

\footnotetext{
C. Ji $\cdot$ J. Wang $(\triangle) \cdot$ W. Zhang $\cdot$ J. Liu $\cdot$ H. Wang $\cdot$ L. Gao $\cdot$

T. Liu $(\square)$

Key Laboratory of Biofuels, Qingdao Institute of Bioenergy and Bioprocess Technology, Chinese Academy of Sciences, Qingdao, Shandong 266101, People's Republic of China e-mail: wangjf@qibebt.ac.cn

e-mail: liutz@qibebt.ac.cn

C. Ji

University of Chinese Academy of Sciences, Beijing 100049, People's Republic of China
}

way to efficiently utilize the nitrogen source with minimum of waste.

Keywords Attached cultivation - Aucutodesmus obliquus (Chlorophyceae) $\cdot$ Nitrogen $\cdot$ Growth $\cdot$ Total lipids

\section{Introduction}

Oleaginous microalgae, a group of photosynthetic organisms that accumulate high content of total lipids under various conditions, are considered as some of the most promising candidates for sustainable liquid biofuel production (Chisti 2008; Hu et al. 2008). However, except for a few small scale drop-in tests, this idea of microalgae biofuel is still largely limited in the test tube level. The major obstruction that hampers its industrialization is the severe shortage of cheap algal biomass feedstock. Although microalgae are supposed to have a high photon to phyto-mass conversion efficiency and theoretically can produce

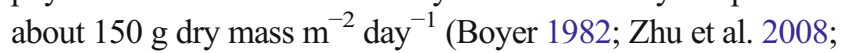
Tredici 2010), the reported outdoor biomass yields are generally less than $40 \mathrm{~g} \mathrm{~m}^{-2}$ day $^{-1}$ using conventional open ponds and closed photobioreactors (Brennan and Owende 2010; Mata et al. 2010).

Recently, an improvement in microalgae biomass productivity with the technology of "attached cultivation" has been announced in which dense algal cells are attached on artificial supporting surfaces and then sealed in a glass chamber with multiple layer structure, so that the solar photon flux of 1,5002,000 $\mu \mathrm{mol}$ photons $\mathrm{m}^{-2} \mathrm{~s}^{-1}$ was diluted and used efficiently (Liu et al. 2013). Biomass productivity of 50 to $80 \mathrm{~g} \mathrm{~m}^{-2}$ day ${ }^{-1}$ was obtained with the oleaginous microalga Aucutodesmus obliquus at Qingdao, China, with this technology, which is 500 to $700 \%$ higher than that of conventional open ponds under the same climate and light conditions. The cultivation of Botryococcus braunii (Cheng et al. 2013) also has proved the 
efficiency of this method. Some similar cultivation methods presented by other research groups showed potential advantages in effluent treatments, biomass accumulation, and harvest. Shi et al. (2007) proposed a twin-layer system in which Chlorella vulgaris and Scenedesmus rubescens removed nitrate, phosphate, and ammonium efficiently from municipal wastewater. Mulbry et al. (2008) set up a pilot-scale algal turf scrubber raceway and evaluated productivity, nutrient content, and nutrient recovery using filamentous green algae grown in outdoor raceways at different loading rates of raw and anaerobically digested dairy manure effluent. Boelee et al. (2011) investigated the capacity of microalgal biofilms as a posttreatment step for the effluent of municipal wastewater treatment plants and demonstrated that microalgal biofilms could be used for removing both nitrogen and phosphorus from municipal wastewater effluent. Naumann et al. (2012) demonstrated the suitability of a new solid-state PBR, the twin-layer system, to cultivate some microalgae (Isochrysis sp. T.ISO, Tetraselmis suecica, Phaeodactylum tricornutum, Nannochloropsis sp.). Zamalloa et al. (2013) established an A/I stage system in which domestic wastewater was subjected to a chemical biological adsorption (A stage), followed by treatment in an innovative roof installed parallel plate microalgae biofilm reactor for nutrient immobilization (I stage). This system could effectively decrease the concentrations of the total COD, N, and the P. These studies proved that the immobilized biofilm cultivation system was stable long-term and basically contamination free; moreover, this system had low overall energy consumption, especially for the harvesting process. Even though this kind of biofilm cultivation method exhibited great potential in improving the microalgae biofuel industry, many aspects of this novel method are still far from optimized. One of the major concerns when applying this attached cultivation technology is the method and strategy to efficiently supply the nitrogen source. Different to conventional suspended cultivation, the microalgae cells are separated from the majority of the aqueous medium in the attached cultivation system (Fig. 1). In our previous research, to keep the stability and adequacy of the nutrient environment, freshly prepared full strength BG-11 medium flowed through the cultivation surface in a non-recycled "one-way" manner. It was obvious that this kind of nutrient supply strategy was not applicable for the actual large scale cultivation.

Many studies have assessed the effects of nitrogen sources on microalgae. Many researchers have reported on the optimum nitrogen source, concentration, and supply strategy for different algae species in different cultivation systems (e.g., Li et al. 2008; Lin and Lin 2011). However, the majority of these studies used conventional aqueous-suspended cultivation systems and the derived "optimized" values might not necessary be the case for the attached cultivation system. Generally, nitrogen starvation reduces biomass accumulation but boosts the synthesis of total lipids, especially the neutral triacylglycerides (TAG) (e.g., Cho et al. 2011; Li et al. 2008; Lourenco et al. 2002). This means that, in most cases, microalgae total lipids are produced in two steps, viz. biomass proliferation in the first step under moderate conditions and then total lipid induction in the second step under adverse conditions (especially nitrogen starvation and high light). However, in view of cultivation efficiency, simultaneous accumulation of total lipids with microalgae growth would be preferable.

Here, by studying the effects of nitrogen concentration and medium volume on the growth and total lipid accumulation of A. obliquus with our attached cultivation method, two basic but critical issues of nitrogen supply strategies for biofilm cultivation with circulated aqueous medium were investigated: (1) how much nitrogen was required to gain the highest biomass/total lipid productivity? and (2) how to supply this dose of nitrogen to the algal cells? The results also shed some light on the potential of nitrogen utilization and water saving of this attached cultivation method and should benefit the commercialization of this technology.

\section{Materials and methods}

The microalga Acutodesmus obliquus was locally isolated at Qingdao, China, and maintained in BG-11 medium (Stanier et al. 1971). The culture of A. obliquus was inoculated in glass columns $(0.5 \mathrm{~m}$ long, $0.05 \mathrm{~m}$ in inner diameter with $0.7 \mathrm{~L}$ working volume) under a continuous illumination of $100 \mu \mathrm{mol}$ photons $\mathrm{m}^{-2} \mathrm{~s}^{-1}$. The algal culture was aerated continuously with $\mathrm{CO}_{2}$ enriched air flow (air: $\mathrm{CO}_{2}=1: 0.02, v: v$ ) at a rate of $0.25 \mathrm{v} \mathrm{v}^{-1} \mathrm{~min}^{-1}$. The temperature was $25 \pm 1{ }^{\circ} \mathrm{C}$. The algal biomass was harvested at late exponential phase (ca. 7 days after inoculation) by gravity sedimentation for $12 \mathrm{~h}$.

\section{The attached cultivation system}

The attached culture cultivation system consisted of a $0.2 \mathrm{~m} \times$ $0.3 \mathrm{~m}$ glass plate $(0.003 \mathrm{~m}$ thick) placed inside a $0.35 \mathrm{~m} \times$ $0.2 \mathrm{~m} \times 0.1 \mathrm{~m}$ glass chamber. One surface of the glass plate, which would be illuminated in the following cultivation, was covered by a layer of filter paper. The algae cells were evenly vacuum filtered onto $0.45 \mu \mathrm{m}$ nitrate cellulose/cellulose acetate filter membranes (Motimo Co., China) to form an attached algal disk with $10 \pm 0.5 \mathrm{~cm}^{2}$ area, which was then placed onto the filter paper (Fig. 1a). When making these algal disks, an aliquot of inoculum containing $10 \mathrm{mg}$ biomass was gently pipetted into the vacuum filtration device and then the pump was started to produce a vacuum of $-0.02 \mathrm{MPa}$. After 5 to $10 \mathrm{~s}$, the algal biomass would be evenly attached onto the membrane. The glass chamber, including the glass plate and the attached algal disks, was placed on an iron rack with a tilt angle of $5^{\circ}$ against the horizontal plane. Several cold white fluorescence lamps (FSL T8 36W, Foshan Electrical Lighting Co., Ltd., China) were placed above the glass 
Fig. 1 Schematic diagram of the attached photobioreactor. a Schematic diagram of the cultivation module. b Schematic diagram of the whole photobioreactor. The aqueous medium was propelled by a peristaltic pump to circulate inside the system. c Photograph of the photobioreactors during experiments

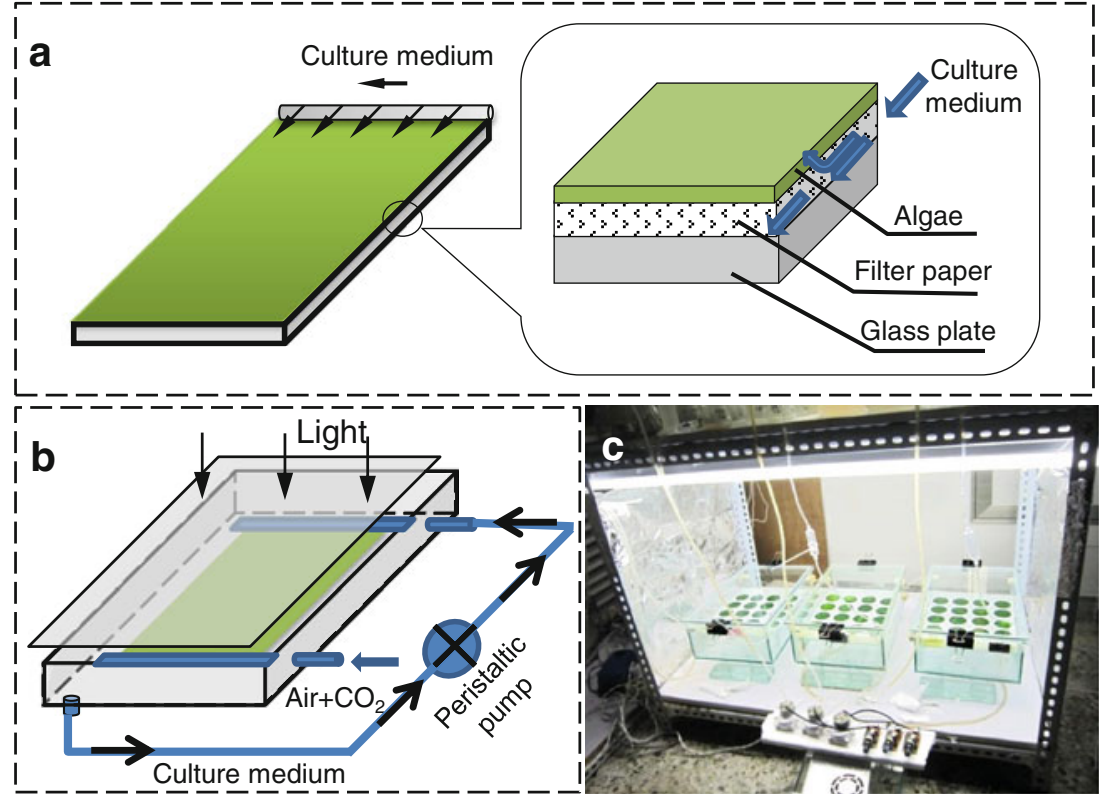

chamber, and the light intensity measured at the algal disks was $100 \pm 5 \mu \mathrm{mol}$ photons $\mathrm{m}^{-2} \mathrm{~s}^{-1}$. The medium was dripped $\left(0.06 \mathrm{~L} \mathrm{~h}^{-1}\right)$ into the space between the filter paper and glass plate from a perforated nylon tubing which was placed on the upper edge of the glass plate. The filter paper membranes as well as the attached algae disks were well wetted but undetached during the experiment as the medium is soaked in. The medium was pumped by a mini peristaltic pump (TP12DC 12V, Guangzhou JU PlasFitting Technology Co., Ltd., China) for circulation inside the system (Fig. 1b). Deionized water was added to the systems every $12 \mathrm{~h}$ to make up the volume loss due to evaporation. A photograph of the photobioreactor during experiments is shown in Fig. $1 \mathrm{c} . \mathrm{CO}_{2}-$ enriched compressed air (air: $\mathrm{CO}_{2}=1: 0.02, v: v$ ) was continuously injected into the glass chamber with a flow rate of $60 \mathrm{~L} \mathrm{~h}^{-1}$. The temperature inside the chamber was $25 \pm 1{ }^{\circ} \mathrm{C}$.

\section{Experimental design}

Two experiments were performed to study the nitrogen supply strategy for the attached cultivation. In the first experiment, the attached $A$. obliquus were cultivated with 1 L of BG-11 medium containing different quantities of $\mathrm{NaNO}_{3}$. In the second experiment, the effect of culture volume was investigated by cultivating the attached A. obliquus in different volumes of medium containing same amount of $\mathrm{NaNO}_{3}(0.15 \mathrm{~g}, 1.76$ mmole). For both of the experiments, fresh algal cells of ca. $160 \mathrm{mg}$ dry mass were evenly filtered onto 16 pieces of membranes which were then used to inoculate a single photobioreactor. As a result, each photobioreactor had $160 \mathrm{~cm}^{2}$ of effective cultivation surface and ca. $10 \mathrm{~g} \mathrm{~m}^{-2}$ of initial biomass density. The attached algal cells were cultivated for 7 days before the following analyses were performed. The cultivation for each treatment was repeated three times under the same conditions. When sampling, five pieces of membranes were taken to measure the dry weight separately, i.e., $5 \times 3=15$ replicates. Five pieces of membranes were taken and combined together for measuring the lipid and nitrogen, i.e., three replicates.

\section{Growth analysis}

The biomass density and biomass productivity were measured according to the method of Liu et al. (2013). The attached algal membranes were sampled after 7 days of cultivation. The algal biomass on the each membrane was detached and washed three times with deionized water. Then, the algal biomass was filtered onto pre-weighted $0.45 \mu \mathrm{m} \mathrm{GF} / \mathrm{C}$ filters (Whatman, England) and oven dried to constant weight at $105^{\circ} \mathrm{C}$ for $12 \mathrm{~h}$. The weight difference between the GF/C filter and the filter plus algae was considered as the total biomass of the algal sample $\left(W_{\mathrm{t}}, \mathrm{g}\right)$, and the areal biomass density $\left(D W_{\mathrm{t}}, \mathrm{g} \mathrm{m}^{-2}\right)$ was calculated as

$D W_{t}=W_{t} / 0.001$

Where the 0.001 represents the footprint area $\left(\mathrm{m}^{2}\right)$ of the attached algal biomass. According to our pilot research, this footprint area was unchanged during the cultivation of 7 days even though both the biomass and the thickness were significantly increased.

The biomass productivity $\left(\mathrm{g} \mathrm{m}^{-2}\right.$ day $^{-1}$ ) for the attached cultivation was calculated as

Productivity $=\left(D W_{t}-D W_{0}\right) / t$ 
Where $D W_{0}$ is the biomass density of day 0 and $t$ represented the cultivation time, viz. 7 days.

Total lipid content and total lipid composition analysis

The microalgae biomass was washed down and harvested by centrifugation at $10,000 \times \mathrm{g}$ for $5 \mathrm{~min}$ and then lyophilized to analyze the total lipid content and total lipid composition according to the method of Chen et al. (2012).

The total lipid content was determined by gravimetric analysis. Approximately, $50 \mathrm{mg}$ of lyophilized algae powder was triturated in a mortar and then mixed with $7.5 \mathrm{~mL}$ chloroform/methanol $(1: 2, v / v)$ at $37^{\circ} \mathrm{C}$ overnight. The mixture was then centrifuged at $8,000 \times g$ for $5 \mathrm{~min}$. The supernatant was collected, and residual biomass was extracted once more. The supernatants were combined, and chloroform and $1 \%$ sodium chloride solution were added to a final volume ratio of 1:1:0.9 (chloroform:methanol:water). The new mixture was centrifuged at $8,000 \times g$ for $10 \mathrm{~min}$, and subnatant was collected to a pre-weighted vitreous vial. The solution was desolvated under nitrogen flow and dried to constant weight at $60{ }^{\circ} \mathrm{C}$ in a vacuum drying oven. The total lipid content was calculated as a percentage of the dry weight of the algae.

The total lipid components were analyzed using a thin layer chromatography system (TLC-FID, MK-6, Iatron Laboratories, Inc., Japan). Samples were dissolved in chloroform to a concentration of $5 \mathrm{~g} \mathrm{~L}^{-1}$ and then spotted onto Chromarod S-III silica coated quartz rods. The rods were developed in two systems: system I, benzene-chloroformacetic (150:60:2, v/v/v), and system II, benzene-hexane $(50: 50, v / v)$. The rods were oven dried at $70{ }^{\circ} \mathrm{C}$ for $1 \mathrm{~min}$ before they were scanned in the Iatroscan analyzer operated at a flow rate of $160 \mathrm{~mL} \mathrm{~min}^{-1}$ for hydrogen and $2 \mathrm{~L} \mathrm{~min}^{-1}$ for air. The separated total lipids were identified by comparing their retention time with pure standards (Sigma, USA). The quantities of individual components were estimated from the peak areas of pure standards, and TAG content was obtained consequently.

\section{Determination of nitrogen content}

The quantity of nitrogen in the algal biomass (nitrogen content, $\mathrm{g} \mathrm{g}^{-1} \mathrm{DW}$ ) was measured by an elemental analyzer (Elemental vario EL III, Germany), with combustion temperature of $1,140{ }^{\circ} \mathrm{C}$ and helium as carrier gas.

The nitrate concentration in the culture medium was measured according to the method described by Collos et al. (1999). An aliquot of $2 \mathrm{~mL}$ culture broth or culture medium was centrifuged at $10,000 \times g$ for $5 \mathrm{~min}$ to collect the supernatant. The optical density of the supernatant at $220 \mathrm{~nm}\left(\mathrm{OD}_{220}\right)$ was measured, and the mole concentration of nitrate $(C, \mathrm{mM})$ was calculated according to the standard curve

$C=0.2763 \mathrm{OD}_{220}+0.0006\left(r^{2}>0.99\right)$

Where $C$ is the nitrogen concentration $(\mathrm{mM})$, and $\mathrm{OD}_{220}$ is in the range of $0.1-1.0$. In case of $\mathrm{OD}_{220}>1$, the supernatant was diluted with deionized water before measuring.

The effective nitrogen utilization efficiency $(\eta)$, a parameter describing the portion of nitrogen transferred from culture medium to algal biomass, was calculated as

$\eta=\left(M_{\text {end }} \times W_{\text {end }}-M_{\text {ini }} \times W_{\text {ini }}\right) /\left(14 \times C_{\text {ini }} \times V\right)$

Where $M_{\text {ini }}$ and $M_{\text {end }}$ represent the nitrogen content in the algal biomass at day 0 and 7, respectively, $W_{\text {ini }}$ and $W_{\text {end }}$ represent the total biomass $(\mathrm{mg})$ in the reactor at day 0 and 7, respectively, and $C_{\text {ini }}$ and $V$ represent the initial nitrogen concentration $(\mathrm{mM})$ and volume $(\mathrm{L})$ of the culture medium.

The medium nitrate loss ratio $(\sigma)$, a parameter describing the portion of medium nitrogen that neither deposited inside the algal biomass nor remained as nitrate, was calculated as

$\sigma=1-\eta-C_{\text {end }} / C_{\text {ini }}$

Where $C_{\text {end }}$ represents the nitrate concentration $(\mathrm{mM})$ in the culture medium at day 7 .

Statistical analysis

The one-way ANOVA accompanied with Duncan's test were used to assess differences between treatments using SPSS 11.0 (SPSS Inc., USA). If $p<0.05$, the difference was considered significant.

\section{Results}

The nitrogen concentration significantly affected the growth and total lipid accumulation of the attached $A$. obliquus. With an increase of nitrogen concentration, the biomass productivity increased steeply from $3.99 \pm 0.16$ to $9.16 \pm 0.04 \mathrm{~g} \mathrm{~m}^{-2}$ day $^{-1}$ in the range of 0 to1.76 mmole and then leveled off (Fig. 2a). The highest total lipid contents of ca. $0.45 \mathrm{~g} \mathrm{~g}^{-1} \mathrm{DW}$ were obtained for the 0 to 0.88 mmole nitrogen treatments, and the highest TAG content of $0.82 \pm 0.01 \mathrm{~g} \mathrm{~g}^{-1} \mathrm{TL}$ was obtained in the nitrogen free treatment (Fig. 2b, c). The total lipids and TAG productivities reached the highest values of $3.61 \pm 0.17$ and $2.35 \pm 0.08 \mathrm{~g} \mathrm{~m}^{-2} \mathrm{day}^{-1}$, respectively, in the 1.76 mmole nitrogen treatment. 

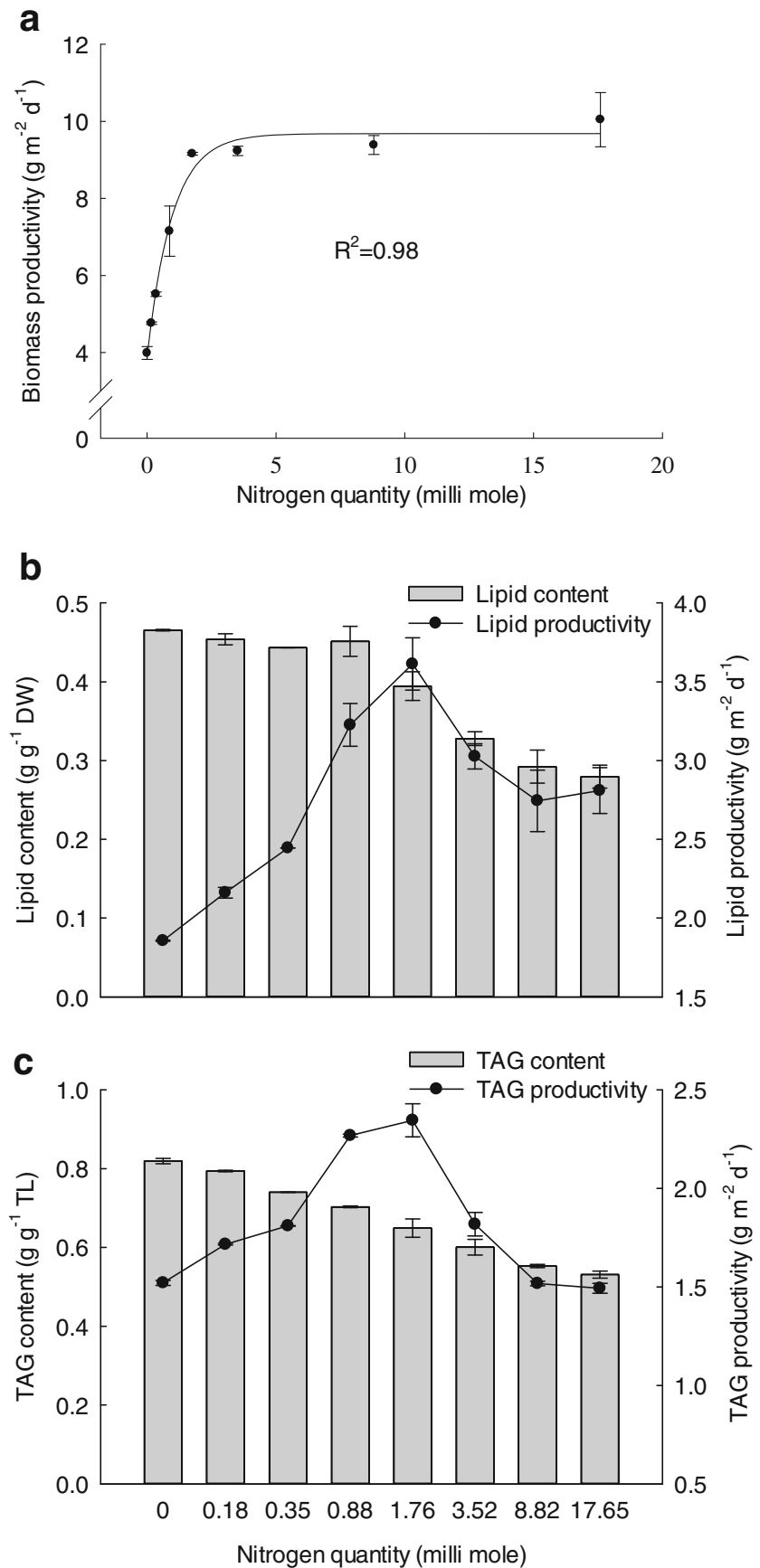

Fig. 2 The effect of nitrate quantity on the growth and lipid accumulation of attach cultivated $A$. obliquus. The results are mean \pm standard deviation of attached $A$. obliquus that had been cultivated for 7 days. One liter of BG-11 medium that contained different quantities of $\mathrm{NaNO}_{3}$ was circulated inside the system. The replicates for growth and lipid analyses were 15 and 3 , respectively

The effects of medium volume were further explored by supplying 1.7 mmole sodium nitrate in different volumes of culture medium. The volume of the medium affected the growth and total lipids accumulation less compared with the nitrogen concentration. The biomass productivity ranged from $7.42 \pm 0.65$ to $9.15 \pm 0.73 \mathrm{~g} \mathrm{~m}^{-2} \mathrm{day}^{-1}$, and the maximum value was reached at the medium volume of $1.0 \mathrm{~L}$ (Fig. 3a). In case of the total lipid content and total lipid productivity, there were no significant differences between the different volume treatments (Fig. 3b, $p>0.05$ ). The TAG content and productivity reached the maximum values of $0.68 \pm 0.04 \mathrm{~g} \mathrm{~g}^{-1} \mathrm{TL}$ and $2.53 \pm$ $0.34 \mathrm{~g} \mathrm{~m}^{-2}$ day $^{-1}$, respectively, for the medium volume of
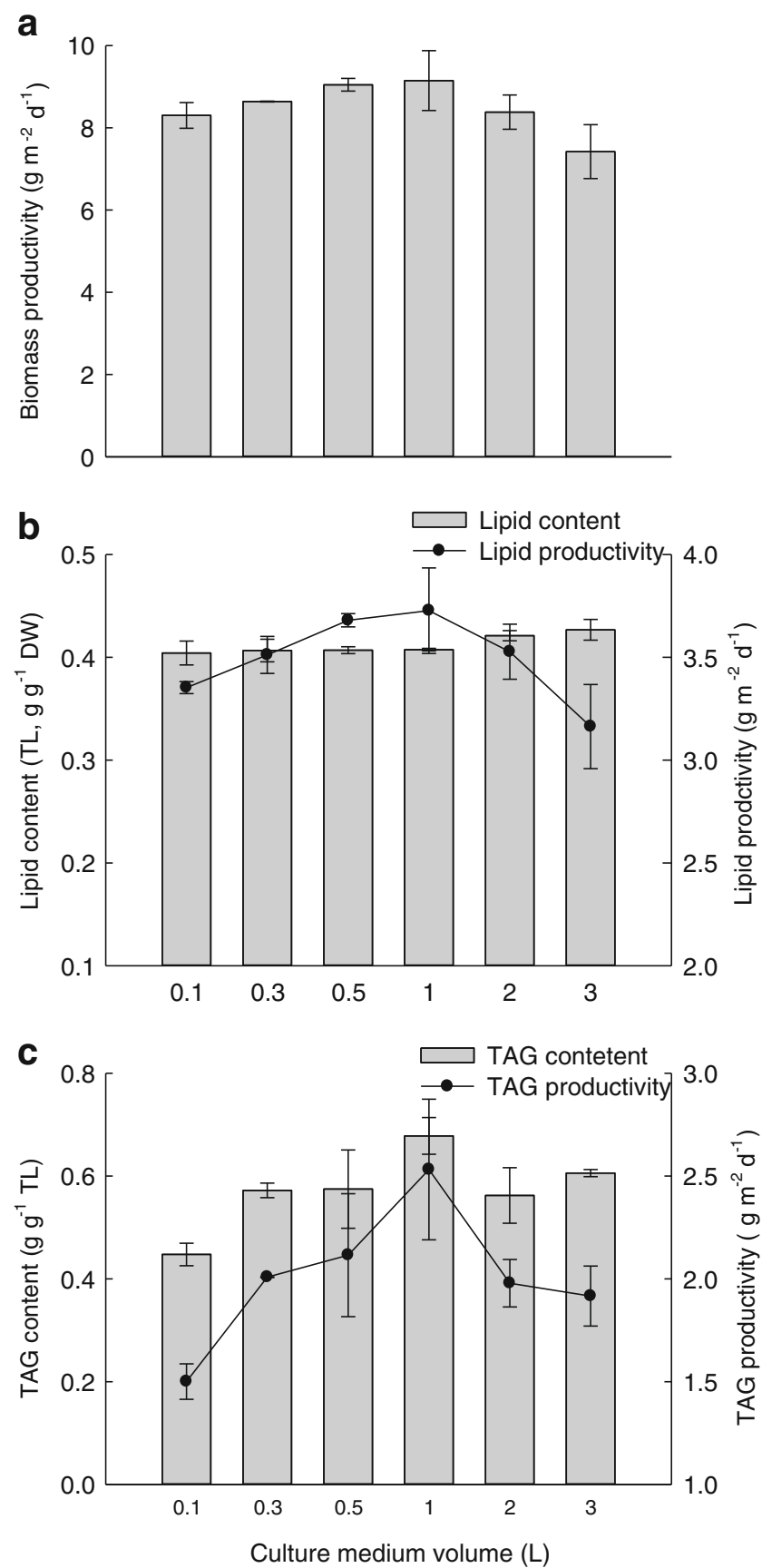

Fig. 3 The effect of medium volume on the growth and lipid accumulation of attach cultivated $A$. obliquus. The results mean \pm standard deviation of attached $A$. obliquus that had been cultivated for 7 days. Different volume of BG-11 medium that same quantity of $\mathrm{NaNO}_{3}$ (1.76 millimole) was circulated inside the system. The replicates for growth and lipid analyses were 15 and 3 , respectively 
1.0 L, which were significantly higher than for the $0.1 \mathrm{~L}$ treatment (Fig. 3c, $p<0.05$ ).

After 7 days of attached cultivation, the dry mass based nitrogen contents decreased from 8 to $10 \%$ to $1-3 \%$ (Table 1). With increased medium volume, the nitrogen content in the biomass decreased as did the portion of nitrogen taken up by the cells, while the portion of nitrogen "lost" increased from 6.83 to $69.94 \%$ (Table 1).

\section{Discussion}

The attached microalgal cultivation technology is different to the conventional suspended cultivation methods (e.g., open pond or closed photobioreactors) at least in the following aspects: (1) Illumination - for the suspended methods, the algal cells continuously shuttle between light and dark regimes, whereas the attached algal cells are somehow "immobilized" so that the light condition is relatively stable if not considering the natural fluctuation of light sources, (2) nutrient environment - for the suspended methods, the algal cells are surrounded by large volume of aqueous nutrient medium $\left(<10 \mathrm{~g} \mathrm{~L}^{-1}\right.$ in biomass density), while for the attached system in which the algal cells and medium are separated, the medium volume can be reduced greatly so that the nutrient concentration can be changed more swiftly and more dramatically. Moreover, the nutrient reaches the attached algal cells mainly through capillaceous absorption and diffusion, which may affect the assimilation process, (3) $\mathrm{CO}_{2}$ transfer - in case of suspended cultivation, the carbon source supplied with $\mathrm{CO}_{2}$ gas must firstly dissolve in the aqueous medium to form a diluted solution of $\mathrm{HCO}_{3}{ }^{-}, \mathrm{CO}_{3}{ }^{2-}$, and $\mathrm{CO}_{2}$ and then be taken up by the algal cells (Van den Hende et al. 2012). For the attached system, this approach becomes more efficient. The cells are covered by only a thin film of water, the diffusion pathways of $\mathrm{CO}_{2}$ from the location of phase transition to the cells is greatly shortened and the absorption surfaces (surface to volume ratio) is enlarged so that the concentrated $\mathrm{CO}_{2}$ gas reaches the algal cells easier. These differences in supply patterns of light, nutrient, as well as $\mathrm{CO}_{2}$ between the suspended and attached methods are presumed to alter the key metabolic pathways in algal cells (e.g., photosynthesis and total lipids synthesis), and accordingly, the biotechnology for mass cultivation.

With the increase in nitrogen quantity, the total lipids as well as the TAG content gradually decreased, indicating that the carbon flow inside the algal cells is dynamically regulated between carbohydrate synthesis and total lipid synthesis by nitrogen conditions ( $\mathrm{Li}$ et al. 2010, 2011). Higher and lower nitrogen content led to decreased total lipid and TAG productivities (Fig. 2b, c). Similar results were also reported by Wang et al. (2013), who found the highest productivity of astaxanthin was only reached in moderate light stress conditions.

The growth and total lipid accumulation properties for this attached cultivation study with optimized circulated medium (1.0 L, 1.7 mmole nitrogen) were similar to that of uncirculated medium in our previous study (Liu et al. 2013). Accordingly, an operational nitrogen supply strategy for attached cultivation of A. obliquus is proposed as circulating ca. $60 \mathrm{~L}$ of BG-11 medium containing $1 / 10$ nitrate for $1 \mathrm{~m}^{2}$ of cultivation surface with an initial biomass of ca. $10 \mathrm{~g} \mathrm{~m}^{-2}$. With this nitrogen supply strategy, the highest total lipid and TAG productivities would be achieved with minimum compromise of the biomass accumulation. Noteworthy points for this nitrogen strategy are: (1) it was applied in a subsaturated illuminating condition of $100 \mu \mathrm{mol}$ photons $\mathrm{m}^{-2} \mathrm{~s}^{-1}$ in this study. The light saturation point for the attached $A$. obliquus was about $150 \mu \mathrm{mol}$ photons $\mathrm{m}^{-2} \mathrm{~s}^{-1}$, over which the biomass productivity increased more slowly (or decreased) with the increase of light intensity (Liu et al. 2013); (2) The high content of TAG could be induced in only 7 days of cultivation and the productivity was higher than that of suspended cultivation (20-50 \% DW) (Hu et al. 2008). With these two characters, the TAG productivity was expected to reach over $25 \mathrm{~g} \mathrm{~m}^{-2}$ day ${ }^{-1}$ if this nitrogen supply strategy was applied to a multiple layer attached cultivation bioreactor in 10

Table 1 The nitrogen utilization property for attached cultivation of $A$. obliquus with same nitrate quantity in different medium volume

\begin{tabular}{lrllrr}
\hline Volume $(\mathrm{L})$ & $C_{\text {ini }}(\mathrm{mM})$ & $C_{\text {end }}(\mathrm{mM})$ & $M_{\text {end }}(\% \mathrm{DW})^{\mathrm{a}}$ & $W_{\text {end }}(\mathrm{mg})^{\mathrm{b}}$ & \multicolumn{1}{c}{$\eta(\%)$} \\
\hline 0.1 & $17.26 \pm 0.10$ & $0.39 \pm 0.01$ & $3.18 \pm 0.01$ & $1066.72 \pm 34.85$ & 90.93 \\
0.3 & $5.66 \pm 0.15$ & $0.17 \pm 0.01$ & $2.69 \pm 0.02$ & $1104.56 \pm 1.24$ & 74.94 \\
0.5 & $3.31 \pm 0.23$ & $0.13 \pm 0.001$ & $2.71 \pm 0.01$ & $1150.16 \pm 17.31$ & 83.14 \\
1.0 & $1.73 \pm 0.01$ & $0.06 \pm 0.004$ & $2.18 \pm 0.05$ & $1161.60 \pm 51.46$ & 55.66 \\
2.0 & $0.84 \pm 0.02$ & $0.03 \pm 0.003$ & $2.14 \pm 0.06$ & $1075.68 \pm 36.61$ & 47.66 \\
3.0 & $0.61 \pm 0.04$ & $0.09 \pm 0.001$ & $1.64 \pm 0.01$ & $968.24 \pm 43.20$ & 41.15 \\
\hline
\end{tabular}

${ }^{\mathrm{a}} M_{\text {ini }}$ Was $8.68 \pm 0.01 \% \mathrm{DW}$ for all treatments

${ }^{\mathrm{b}} W_{\text {ini }}$ was $137.2 \pm 0.11 \mathrm{mg}$ for all treatments $C_{\text {ini }}$ and $C_{\text {end }}$ represent the nitrate concentration in culture medium at day 0 and 7 , respectively; $M_{\text {ini }}$ and $M_{\text {end }}$ represent the nitrogen content deposited in algal biomass at day 0 and 7, respectively; $W_{\text {ini }}$ and $W_{\text {end }}$ represent the total biomass in the reactor at day 0 and day 7, respectively; $\eta$ and $\sigma$ represent the effective nitrogen utilization efficiency and the medium nitrate loss ratio, respectively. Data are mean \pm standard deviation of three replicates 
times of light dilution rate as proposed by us previously (Liu et al. 2013). Meanwhile, the attached cultivation of microalgae to produce biofuel could be operated in a continuous mode, which means that a large amount of TAG could be produced directly in one-step continuous mode without increasing the light intensity or changing the composition of the medium. For the suspended cultivation, continuous production of secondary metabolites from microalgae is generally very low in efficiency and is limited to the production of high value bioactives (Aflalo et al. 2007; García-Malea et al. 2009). In case of producing cheap metabolites in large scale (e.g., TAG for biofuel), the batch mode (two-step) is the prevailing strategy in which the microalgae cells are first cultivated in unstressed conditions to accumulate biomass and then transferred to adverse conditions to induce the synthesis and accumulation of the target metabolites (Heieh and Wu 2009; Ratha et al. 2013).

It is well-known that the water consumption for traditional aquatic suspended cultivation methods is very huge. For example, Ozkan et al. (2012) showed that 1,618 and 2,857 L of water are required to produce $1 \mathrm{~kg}$ of biomass in a biofilm PBR and an open pond system, respectively. Moreover, according to Jorquera et al. (2010), for conventional open ponds and flatplat photobioreactors, ca. 300 and $100 \mathrm{~L}$ water are used per $1 \mathrm{~m}^{2}$ of space. Without doubt, such water consumption would be an unaffordable burden and non-sustainable for the production of microalgae biomass for biofuels and other resources. In the present study, it was found that a medium volume of $0.1 \mathrm{~L}$ was sufficient to wet $0.06 \mathrm{~m}^{2}$ of filter paper (or in another words, cultivation surface). During the cultivation, ca. $60 \mathrm{~mL}$ of water was lost by evaporation every $24 \mathrm{~h}$. This water loss could be greatly reduced if the reactors were better sealed and if the inlet gas was saturated prior injecting into the chamber. Accordingly, it is estimated that the algal cells potentially can be grown in attached cultivated with $<2.0 \mathrm{~L}$ of aqueous medium per $1 \mathrm{~m}^{2}$ cultivation surface, which is only a tiny fraction of the medium volume of conventional open ponds as well as other unsealed single layer biofilm bioreactors (Ozkan et al. 2012). There is a big gap between this potential of $<2.0 \mathrm{~L} \mathrm{~m}^{-2}$ and the "suggested" medium volume of ca. $60 \mathrm{~L} \mathrm{~m}^{-2}$. This volume gap might be reduced by changing the nutrient supply method from the current batch type "feed-and-forget" method to a more precise and sophisticated process coupled with nutrient sensors.

In this study, we found the algal cells tended to store more nitrogen if the medium has a higher initial nitrogen concentration (Table 1). The physiological mechanisms behind this phenomenon might relate to the nitrogen distribution inside the attached algal layer, which is an interesting topic to explore in the future. The reason for the nitrogen "lost" might because denitrification by bacteria that metabolize the nitrate in the medium into $\mathrm{NH}_{3}, \mathrm{~N}_{2}$, or $\mathrm{N}_{2} \mathrm{O}$ (Harter et al. 2013; Rysgaard et al. 1995; Subashchandrabose et al. 2011). According to these results, preparing nitrogen concentrated medium by dissolving the required amount of nitrogen in a small volume is the best way to achieve nitrogen high nitrogen utilization efficiency with a minimum of waste. This conclusion was similar with that of Mulbry et al. (2008) who found that the absolute amounts of $\mathrm{N}$ recovered in the algal biomass generally increased with loading rate during the treatment of dairy manure effluent using pilot-scale algal turf scrubbers. Boelee et al. (2011) also found that in the post-treatment of municipal wastewater effluent with microalgae biofilms, the internal $\mathrm{N}$ content of the microalgae increased with increasing loading rates until the maximum loading rates of $1.0 \mathrm{~g} \mathrm{NO}_{3}-\mathrm{N} \mathrm{m}^{-2}$ day $^{-1}$. From this point of view, the idea of waste water treatment by microalgae with "biofilm" reactors (Shi et al. 2007) need to be critically reviewed because the waste water has a huge volume with relative low nitrogen concentrations so that the portion of nitrogen fixed inside the algal biomass might be relative small.

In conclusion, the growth and total lipid accumulation during attached cultivation of $A$. obliquus with circulated medium was mainly controlled by nitrogen concentration rather than medium volume. An optimized nitrogen supply strategy for high efficiency production of biomass and total lipids simultaneously under subsaturated illumination of $100 \mu \mathrm{mol}$ photons $\mathrm{m}^{-2} \mathrm{~s}^{-1}$ was proposed as circulating ca. $60 \mathrm{~L}$ of BG-11 medium containing $1 / 10$ of nitrate per $1 \mathrm{~m}^{2}$ of cultivation surface with an initial biomass concentration of $10 \mathrm{~g} \mathrm{~m}^{-2}$. The TAG productivity is expected to improve significantly if a multiple layer attached cultivation bioreactor with 10 times of light dilution rate is applied. This medium volume of $60 \mathrm{~L} \mathrm{~m}^{-2}$ can potentially be reduced to $<2.0 \mathrm{~L} \mathrm{~m}^{-2}$. Dissolving the nitrogen source in a small volume is the best way to efficiently utilize the nitrogen with a minimum of waste.

Acknowledgments This work was supported by Qibebt (CAS)-Boeing Joint Research Laboratory for Sustainable Aviation Biofuel, the Key Technologies R\&D Program from the Ministry of Science and Technology of China (2011BAD14B01), and the Solar Energy Initiative Plan (KGCX2-EW-309) from the Chinese Academy of Sciences.

\section{References}

Aflalo C, Meshulam Y, Zarka A, Boussiba S (2007) On the relative efficiency of two- vs. one-stage production of astaxanthin by the green alga Haematococcus pluvialis. Biotechnol Bioeng 98:300305

Boyer JS (1982) Plant productivity and environment. Science 218:443448

Brennan L, Owende P (2010) Biofuels from microalgae - a review of technologies for production, processing, and extractions of biofuels and co-products. Renew Sust Energ Rev 14:557-577

Boelee NC, Temmink H, Janssen M, Buisman CJN, Wijffels RH (2011) Nitrogen and phosphorus removal from municipal wastewater effluent using microalgal biofilms. Water Res 45:5925-5933

Chen L, Liu T, Zhang W, Chen X, Wang J (2012) Biodiesel production from algae oil high in free fatty acids by two-step catalytic conversion. Bioresour Technol 111:208-214 
Cheng P, Ji B, Gao L, Zhang W, Wang J, Liu T (2013) The growth, lipid and hydrocarbon production of Botryococcus braunii with attached cultivation. Bioresour Technol 138:95-100

Chisti Y (2008) Biodiesel from microalgae beats bioethanol. Trends Biotechnol 26:126-131

Cho S, Lee D, Luong TT, Park S, Oh YK, Lee T (2011) Effects of carbon and nitrogen sources on fatty acid contents and composition in the green microalga, Chlorella sp. 227. J Microbiol Biotechnol 21: 1073-1080

Collos Y, Mornet F, Sciandra A, Waser N, Larson A, Harrison PJ (1999) An optical method for the rapid measurement of micromolar concentrations of nitrate in marine phytoplankton cultures. J Appl Phycol 11: 179-184

García-Malea MC, Acién FG, Del Río E, Fernández JM, Cerón MC, Guerrero MG, Molina-Grima E (2009) Production of astaxanthin by Haematococcus pluvialis: taking the one-step system outdoors. Biotech Bioeng 102:651-657

Harter T, Bossier P, Verreth J, Bodé S, Van der Ha D, Debeer AE, Boon N, Boeckx P, Vyverman W, Nevejan N (2013) Carbon and nitrogen mass balance during flue gas treatment with Dunaliella salina cultures. J Appl Phycol 25:359-368

Heieh CH, Wu WT (2009) Cultivation of microalgae for oil production with a cultivation strategy of urea limitation. Bioresour Technol 100: 3921-3926

Hu Q, Sommerfeld M, Jarvis E, Ghirardi M, Posewitz M, Seibert M, Darzins A (2008) Microalgal triacylglycerols as feedstocks for biofuel production: perspectives and advances. Plant J 54:621-639

Jorquera O, Kiperstok A, Sales EA, Embiruçu M, Ghirardi ML (2010) Comparative energy life-cycle analyses of microalgal biomass production in open ponds and photobioreactors. Bioresour Technol 101:1406-1413

Li Y, Horsman M, Wang B, Wu N, Lan CQ (2008) Effects of nitrogen sources on cell growth and lipid accumulation of green alga Neochloris oleoabundans. Appl Microbiol Biotechnol 81:629-636

Li Y, Han D, Hu G, Sommerfeld M, Hu Q (2010) Inhibition of starch synthesis results in overproduction of lipids in Chlamydomonas reinhardtii. Biotechnol Bioeng 107:258-268

Li Y, Han D, Sommerfeld M, Hu Q (2011) Photosynthetic carbon partitioning and lipid production in the oleaginous microalga Pseudochlorococcum sp. (Chlorophyceae) under nitrogen-limited conditions. Bioresour Technol 102:123-129

Lin Q, Lin J (2011) Effects of nitrogen source and concentration on biomass and oil production of a Scenedesmus rubescens like microalga. Bioresour Technol 102:1615-1621

Liu T, Wang J, Hu Q, Cheng P, Ji B, Liu J, Chen Y, Zhang W, Chen X, Chen L, Gao L, Ji C, Wang H (2013) Attached cultivation technology of microalgae for efficient biomass feedstock production. Bioresour Technol 127:216-222
Lourenco SO, Barbarino E, Mancini-Filho J, Schinke KP, Aidar E (2002) Effects of different nitrogen sources on the growth and biochemical profile of 10 marine microalgae in batch culture: an evaluation for aquaculture. Phycologia 41:158-168

Mata TM, Martins AA, Caetano NS (2010) Microalgae for biodiesel production and other applications: a review. Renew Sust Energ Rev 14:217-232

Mulbry W, Kondrad S, Pizarro C, Kebede-Westhead E (2008) Treatment of dairy manure effluent using freshwater algae: algal productivity and recovery of manure nutrients using pilot-scale algal turf scrubbers. Bioresour Technol 99:8137-8142

Naumann T, Çebi Z, Podola B, Melkonian M (2012) Growing microalgae as aquaculture feeds on twin-layers: a novel solid-state photobioreactor. J Appl Phycol. doi:10.1007/s10811-012-9962-6

Ozkan A, Kinney K, Katz L, Berberoglu H (2012) Reduction of water and energy requirement of algae cultivation using an algae biofilm photobioreactor. Bioresour Technol 114:542-548

Ratha SK, Prasanna R, Prasad Rachapudi BN, Sarika C, Dhar DW, Saxena AK (2013) Modulating lipid accumulation and composition in microalgae by biphasic nitrogen supplementation. Aquaculture 392-395:69-76

Rysgaard S, Christensen P, Nielsen L (1995) Seasonal variation in nitrification and denitrification in estuarine sediment colonized by benthic microalgae and bioturbating infauna. Mar Ecol Prog Ser 126:111-121

Shi J, Podola B, Melkonian M (2007) Removal of nitrogen and phosphorus from wastewater using microalgae immobilized on twin layers: an experimental study. J Appl Phycol 19:417-423

Stanier RY, Kunisawa R, Mandel M, Cohenbaz G (1971) Purification and properties of unicellular blue-green algae (Order Chroococcales). Bacteriol Rev 35:171-205

Subashchandrabose SR, Ramakrishnan B, Megharaj M, Venkateswarlu K, Naidu R (2011) Consortia of cyanobacteria/microalgae and bacteria: biotechnological potential. Biotechnol Adv 29:896-907

Tredici MR (2010) Photobiology of microalgae mass cultures: understanding the tools for the next green revolution. Biofuels 1:143-162

Van den Hende S, Vervaeren H, Boon N (2012) Flue gas compounds and microalgae: (Bio-)chemical interactions leading to biotechnological opportunities. Biotechnol Adv 30:1405-1424

Wang J, Han D, Sommerfeld M, Lu C, Hu Q (2013) Effect of initial biomass density on growth and astaxanthin production of Haematococcus pluvialis in an outdoor photobioreactor. J Appl Phycol 25:253-260

Zamalloa C, Boon N, Verstraete W (2013) Decentralized two-stage sewage treatment by chemical-biological flocculation combined with microalgae biofilm for nutrient immobilization in a roof installed parallel plate reactor. Bioresour Technol 130:152-160

Zhu XG, Long SP, Ort DR (2008) What is the maximum efficiency with which photosynthesis can convert solar energy into biomass? Curr Opin Biotech 19:153-159 